\title{
La incertidumbre de lo real. La narrativa de los 90 en la Argentina en la confluencia de las cuestiones de género*
}

Por José Amícola

José Amícola es docente de la Facultad de Humanidades y Ciencias de la Educación de la Universidad Nacional de La Plata. Autor del libro Astrología y fascismo en la obra de Arlt.

* Una versión diferente de este trabajo ha aparecido en la revista Foro Hispánico, 24 ("La literatura argentina de los años 90"), Amsterdam/N.York, Rodopi, 2003, pp. 29-41.

1 Para Josefina Ludmer el fin de siglo estaría signado por algunas preocupaciones clave en la literatura argentina que serían: "modernidad y posmodernidad, nación narración; minorías y excluidos, identidades nacionales, sedos, identidades nacionales, sexuales, raciales, culturales ('géneros' de discursos); la representación y la política; territorializaciones y desterritorializaciones, periferias, fronteras, bordes y cuerpos; el problema del lector y de la existencia misma de la literatura en la era de la información visual" (Ludmer, 1994: 9). cuestionamiento ante los límites de la ficcionalidad con respecto a otros géneros considerados hasta este momento como no literaturizados o literaturizables. Es, por ello, que la década de los 90 parece el período del repentino interés por lo fronterizo, como aprendizaje de lo que ha sucedido en las décadas inmediatamente anteriores ${ }^{1}$

En su estudio sobre la novelística argentina de la década del 80 , ha sido mérito de la investigadora Sandra Lorenzano (2001) retratar la rica producción narrativa a partir del fragmento de una totalidad, arriesgando a sintetizar la experiencia lectora a partir de dos modelos para la interpretación, que aparecen como vistos desde una manera tangencial: los novelistas Héctor Tizón y Sylvia Molloy. Tizón representaría en este estudio la marginalidad con respecto al centro dador de prestigio de la capital, al escribir, entonces, desde una provincia alejada de la metrópolis sobre temas de índole no urbana (en contra de la masa poblacional argentina radicada en grandes ciudades). Molloy, por su parte, basando su escritura desde experiencias en el exterior del país (como representante de una sensibilidad lésbica todavía sin cartografiar en el Río de la Plata) sería el otro polo que exhibiría el sentido de la frontera. Sandra Lorenzano nos encamina en su estudio reciente hacia una metodología de trabajo que puede ser muy sugerente, en tanto esta investigadora no pretende agotar un inventario de una supuesta totalidad, sino que ha preferido, en cambio, apostar por la síntesis a partir de las piezas más significativas de una colección sumamente extensa.

Una metodología similar para circunscribirse al mismo período fue adoptada ya por Carmen Perilli (1994), quien, por su parte, no había utilizado la metáfora de "la escritura de la sobrevivencia" como Lorenzano, sino la del "enigma de la realidad" (un título de la novela de Juan Martini, quien sirve de figura icónica de la década, junto con Andrés Rivera). Es interesante destacar aquí que los dos autores ejemplares que Perilli lanza a la visibilidad de

$10 \underline{O f i c i o S}_{\text {Terrestres }}$ 
su análisis anuncian proféticamente lo que vendrá en la década siguiente, en la que, por una parte, la influencia de la hard-boiled novel estadounidense parece ser el disparador, en el sentido de que así como ese género había nacido al calor de una época de crisis de valores institucionales en Estados Unidos entre 1930 y 1950, también la Argentina de la última parte del siglo $X X$ vive una polémica continua por la validez de sus instituciones. Por otra parte también se da la influencia de una novela histórica renovada o, mejor, la nueva mirada de una memoria individual que se propone a sí misma un revisionismo desde los márgenes de la historiografía oficial o canónica.

Tomando como ejemplo el modo de abordaje de Carmen Perilli y Sandra Lorenzano ${ }^{2}$, entonces, las siguientes páginas apuntan a marcar la incidencia de otros modos discursivos de la narrativa a partir de una dupla de narradoras que han producido un cierto impacto en la creación literaria de la última década del siglo XX. Estos dos polos ejemplificadores se hallarían condensados en la producción de Tununa Mercado y Matilde Sánchez.

Las páginas que siguen consideran que es justamente en esos dos tipos de escritura, realizados desde los márgenes del sistema literario, donde se puede percibir una exacerbación de lo sucedido en los períodos anteriores. Es allí, entonces, donde el lento trabajo de taladrar las certezas del realismo eclosiona en una total aceptación por parte de la narrativa actual de la incertidumbre sobre lo real, y también en un arduo trabajo de "recuperación de la memoria" (que será el segundo mot de passe de la década) $)^{3}$.

Concordante con esta temática central, este trabajo pretende abordar, asimismo, las preocupaciones de las imposiciones sociales sobre la sexualidad (una de las definiciones del concepto de gender). Es, por ello, que el presente intento de capta lo sucedido en la última década del siglo XX en la narrativa argentina no podrá prescindir de esbozar algunas reflexiones sobre lo que significa la entrada de la voz de las mujeres en la escritura en general. Estamos lejos ahora de algunos intentos (fallidos) de los años sesenta, en los que se pretendía hacer resaltar en qué medida los textos de ficción escritos por mujeres hacían profusión de adjetivos o profesaban una (ir)racionalidad en los períodos gramaticales que era básicamente diferente de la escritura de los varones. Sabemos ahora que la escritura ha sido fijada y fraguada con la impronta masculina y que las mujeres han adoptado los mismos modos gramaticales, a los que los textos escritos por los hombres han acostumbrado a los lectores, y esto viene sucediendo inclusive en las otras lenguas, aunque algunas como la lengua inglesa hayan tenido el privilegio de una territorialización por parte de la mujer más temprana de lo que sucedió en otras. Sin embargo, hay ahora algo más que llama la atención en la literatura del mundo, y eso tiene que ver con que la participación de las mujeres en la escritura ha permitido ver el mundo femenino desde coordenadas no siempre dictadas por el maravillamiento o el prejuicio masculino ante el modo de ser del otro polo sexual. Una excepción a lo dicho podría encontrarse en los pocos herederos de la narrativa de Manuel Puig, alguien que como nadie tematizó la problemática del gender, pero que ahora más de diez años después de su muerte, cuenta con escasos representantes, entre los que, sin embargo, puede mencionarse al prolífico César Aira de quien me interesa mencionar aquí El bautismo (1991), La prueba (1992) y Cómo me hice monja (1993), en tanto en esas obras se juega con la ambigüedad sexual, y, al mismo tiempo, con las imposiciones sociales sobre la sexualidad, hasta el punto de desenmascarar el juego de negociaciones que empezamos a estudiar como marcas de género (en el sentido de gende")

En el caso de la más reciente narrativa argentina, los textos escritos por varones señalan una situación que llama poderosamente la atención aho
2 Este camino bifronte para caracterizar un período es abordado también por el artículo de Nora Domínguez titulado

"Subjetividades en peligro, subjetividades peligrosas", para oponer justamente la obra de Matilde Sánchez a la de Marcelo Cohen. Véanse las actas del encuentro denominado: "Fin(es) de siglo y modernismo". Congreso

Internacional. Buenos Aires-La Plata, agosto de 1996, Universitat de les Illes Balears, Palma, 2001, volumen II, pp. 547-552.

3 El meticuloso trabajo de cercenamiento de las certidumbres positivistas que daban la base filosófica a la narrativa del siglo XIX y comienzos del siglo XX había ocupado a Macedonio Fernández y a Jorge Luis Borges en la época de las vanguardias históricas. Ellos fueron quienes abrieron la brecha no sólo para la aparición de un modo fantástico que no debe confundirse con el "realismo mágico" de otros países del caribe, agrupados en torno a un animismo in dígena, sino como puro debate dentro de la filosofía occidental apoyada en una teoría de las percepciones que, a su vez, ha hecho crisis y ha permitido así la aparición de dudas contra las certezas cartesianas.

$\underline{\text { OficioS }}_{\text {rerrestres }} 11$ 
4 Así el mencionado Andrés Rivera, con muchas décadas de incidencia en el campo de la narrativa argentina, ganó el Premio Nacional de Literatura en 1992 por su celebrada novela de 1987 La revolución es un sueño eterno, donde hace hablar a una de las voces marginales de las luchas por la independencia con España (el patriota Castelli), inventando un modo singular de novela histórica; mientras Guillermo Saccomanno ganaría el mismo galardón correspondiente a 1999-2000 por su novela El buen dolor. ra ante la llegada en masa de los textos de las escritoras. Me refiero al hecho de que las protagonistas femeninas en los textos masculinos siguen apareciendo como figuras enigmáticas, rodeadas de un halo de misterio erótico, al modo en que Manue Puig describía, a sabiendas, el encanto de Greta Garbo en su último relato, "Mi queridísima esfinge" (Puig, 1990). En esa misma dimensión de aura como sentimiento de ineludible lejanía aparecen tanto la protagonista alemana Hilde Strasser, en La mujer de Strasser, del experimentado Héctor Tizón, como la musa francesa distante e inasible Aude d'Alençon en El intérprete, la extraordinaria novela del joven narrador Néstor Ponce. Y esto sucede, inclusive, como en el caso del personaje de Hilde Strasser, por ejemplo, cuando el narrador (¿masculino?) nos permite la entrada a los pensamientos más íntimos del personaje femenino. Tal vez una flagrante excepción sea la inusitada revelación de una sexualidad femenina devoradora en la última novela de Rodolfo Fogwill titulada programáticamente La experiencia sensible. Con todo, esta inquietante percepción de los apetitos sexuales femeninos en la escritura de un varón puede despertar la sospecha de una muy conocida constelación masculina ante el miedo a la castración, más que un verdadero intento de percibir el mundo femenino. En otro caso opuesto, el de la mujer de El verdugo en el umbral, de Andrés Rivera, cuya supuesta voz de ídishe mome cuenta la historia del desarraigo judío como una especie de pitonisa, nos encontramos también frente a un vacío de significación donde la voz alternativa no parece más que un procedimiento artificioso de cesión de la voz autorial a un personaje de cierto peso, pero que en el fondo podría ser cualquiera, varón o mujer.

Es evidente, entonces, que ninguna pluma masculina podía pintar las tribulaciones de quien sufría un embarazo (no deseado) hasta la llegada de las mujeres al escritorio masculino de la narrativa, y as es muy sugerente y pionero el modo como lograba la malograda escritora argentina Sara Gallardo 1931-1988) esta percepción de un hecho vital para las mujeres a fines de la década del 50 en su novela Enero (1958), publicada cuando la autora tenía 27 años. Por aquella época, sin embargo, las escritoras argentinas eran un escaso puñado que tenía que abrirse paso dificultosamente en el mercado (como lo demuestra también el caso de Silvina Ocampo), y a nadie le resultó demasiado llamativo el poder de una pluma femenina para la pintura de un hecho ajeno al mundo del varón, como el que pintaba la novela de Gallardo. Hoy en día las cosas han cambiado y las mujeres escritoras ya no necesitan ni siquiera justificarse como mujeres, y lo que es más expresarse por encima de la cláusula del pudor borgeano o el lenguaje inventado de Cortázar, como lo hace Luisa Valenzuela en su apología de la menstruación en la novela La travesía (2001). Por el contrario, el público lector ansía conocer cómo piensa y reflexiona una mujer, aunque los premios nacionales de literatura los sigan ganando primariamente los varones ${ }^{4}$

Para la investigadora estadounidense Francine Masiello, por otra parte, la característica de la escritura en la Argentina radicaría en que se ha esmerado en ficcionalizar los grandes relatos totalizadores sobre "la Patria", basándose en la tradición sentada por Sarmiento y en su famosa oposición de "civilización o barbarie" como intento de definir las circunstancias históricas. Así, según sostiene Masiello:

"La cultura argentina, al registrar las prácticas autoritarias estatales que datan del siglo XIX, ha provocado incontables polémicas intelectuales acerca de la crisis de la historia. En consecuencia, generó, como expresión dominante, una narrativa peculiarmente masculina sobre la propia búsqueda de autenticidad y la consiguiente desilusión del intelectual frente a su investigación fallida" (Masiello, 2001: 16-17).

Lo cierto es que las mujeres escritoras se venían conformando con lo más menudo, es decir, con

$12 \underline{\text { Oficios }}_{\text {Terrestres }}$ 
aquello que les dejaba el varón; léase aquí: la intimidad de la casa o de los sentimientos. Y es, por ello, que ningún varón podría contar lo que narra Canon de alcoba (1988) como sí, en cambio, lo ha-

ce Tununa Mercado, o No te olvides de mí (1995), la novela firmada por Susana Silvestri. Lo que narran las mujeres, según Masiello, fue aprendido, en rigor, en el lento ejercicio de lo doméstico (1992,1997: 75 y ss.). Parecería, entonces que, al fin del siglo XX, en la Argentina los narradores varones siguen atrapados en la lógica del siglo XIX cuestionándose, como lo hace el narrador de Respiración artificial de Ricardo Piglia (1980: 94), con la frase grandilocuente: "¿quién de nosotros [varones] escribirá el Facundo?" (De Diego, 2001), lo que desde la perspectiva de gender parece como una insoslayable (y arrogante) actitud masculina por la que se pretendería dar otra interpretación definitoria del ser nacional ${ }^{5}$. Lo cierto es que lo que viene a poner sobre el tapete la nueva preocupación sobre las cuestiones de identidad sexual promueve una discusión en todo el sistema, pues: "e género sexual hace su ingreso ahora para afirmar el poder del margen; permite proponer una doble lectura en el campo de la política e introduce un conflicto en el campo de la representación" (Masiello, 2001: 15)

Si la Argentina estuvo ensimismada en su dilema entre los opuestos de civilización o barbarie, estos mismos polos eran una manera apocalíptica y masculina de enjuiciar un supuesto ser argentino. Las mujeres no tuvieron oportunidad de interveni en esa disputa bizantina, como no fuera como personajes ideales idealizados por los varones. A parti del siglo $X X$, hubo otras batallas enconadas en e campo literario rioplatense de tal magnitud como aquella anterior, encabezada por Sarmiento, y ellas tuvieron que ver con la lucha cuerpo a cuerpo contra el realismo literario liderada por Macedonio Fernández y Jorge Luis Borges, su grandioso discípulo. Una vez impuesta la hegemonía artística de Borges, y derrotado el otro faro masculino del modernismo, Leopoldo Lugones, la encrucijada a la que se vieron enfrentadas las mujeres parece pasar a partir de 1960 por la alternativa entre la fuerza narrativa ya sea de la pluma de Borges o la de Cortázar, como modelos únicos de escritura. Esto puede percibirse también en alguien tan pionera para la escritura de la mujer en la Argentina como Silvina Ocampo quien habiendo empezado a publicar en 1937 no figuraba todavía en la Historia de la Literatura Argentina de 1968, dirigida por Adolfo Prieto (Jitrik, 2000: 462). En rigor, para muchas mujeres la batalla fue muy ardua y esto lo reconocen todas las escritoras, las más tímidas y las más osadas, que hoy tienen acceso a la expresión. Hay conciencia también de que ya no se pide permiso a los varones para imponer un punto de vista femenino, según constata María Rosa Lojo, citando a Silvina Bullrich en su artículo titulado "Pasos nuevos en espacios habituales" (Jitrik, 2000: 20), aunque todavía con mayor o menor ironía se hable entre las escritoras de "escritos inocentes" (Gambado, 1999) o de "la letra de lo mínimo" (Mercado, 1994), como si este pedido de permiso todavía apareciera cerniendo el aire literario del Río de la Plata. Para comprobar el grado de "patriarquía" que se cuela por las letras argentinas bastaría tan solo con saber leer Descanso de caminantes, el texto de anotaciones diarias de Adolfo Bioy Casares, aparecido póstumamente, donde se pasa revista a la actividad tanto literaria como sexual, desde los coturnos que presta la clase (alta) y el derecho al panteón (masculino), que aquí significa también el sitial en la bóveda del cementerio patricio de La Recoleta, así como el Premio Cervantes en 1990 (Bioy Casares, 2001). Sea como fuere, tanto en el caso de Griselda Gambaro, como en el de Tununa Mercado, con proyectos literarios prácticamente opuestos, la agudeza para juzgar las (cambiables) condiciones históricas de sujeción de las escritoras argentinas a un canon masculino todopoderoso es digna de destacar. Así, por
5 Esta vertiente de la escritura masculina, tan importante para Masiello, como característica argentina, y que va rodeada de un hálito de nostalgia y reverencia por los orígenes mixtos de la nacionalidad surge inevitablemente clara en la narrativa de Rivera o Tizón.

$\underline{O f i c i o S}_{\text {rerrestres }} 13$ 
ejemplo, Gambaro comenta en sus notas de trabajo y de viaje la obra de la italiana Natalia Ginzburg con estas palabras:

"Por comparación, qué superficiales parecen muchas narradoras argentinas. Qué minuciosas. Tratamos de probar: que estamos en el mundo, que conocemos nuevas técnicas, que escribimos o no escribimos como mujeres". (Gambado, 1999: 9).

En rigor, podríamos observar que en la disyuntiva que nota esta autora, el peso del pasado bajo la égida del discurso del varón en la escritura de las mujeres en el Río de Plata es todavía una carga, a pesar de todo. De esa disyuntiva sale, con todo, una especie de conciencia productiva que da sentido a las obras de las unas como la escritura de "lo mínimo", entre las que yo contaría no sólo a las ya mencionadas Tununa Mercado y Susana Silvestri, sino también a Hebe Uhart con su indagadora novela sobre gender titulada Señorita. Pero también en el nuevo panorama se avizora la escritura de las otras, es decir la de quienes no se contentan con lo mínimo y que se insertan en la aspiración masculina de la comprensión de los sucesos políticos. El segundo grupo, el de las "maximalistas", comparte con los varones la propia incertidumbre acerca de la realidad que es, en rigor, el punto de mira de este artículo y que ya fuera asociado a la narrativa de Juan José Saer, en una entrevista muy sugerente con el autor que llevaba el título de "El arte de narrar la incertidumbre" (Saavedra, 1993: 172-190). En esta línea me interesa citar especialmente a Luisa Valenzuela con Novela negra con argentinos, a Griselda Gambaro con Después del día de fiesta, y a Matilde Sánchez con El dock.

Es cierto, por otra parte, que el siglo XX se encargó de destruir certezas que el siglo anterior se había esmerado en construir. Las guerras mundiales y los genocidios declararon, como nunca antes, no sólo que el hombre no era el ser más divino de la creación, sino que cualquier intento de establecer la veracidad de la percepción de lo real iba a ser desmentido por las nuevas iconoclasias representadas en primer lugar por los adelantos de las ciencias físicas, así como por las posibilidades de técnicas más perfectas de laboratorio. Así sabemos ahora que la ciencia vino avanzando en una progresión diametralmente opuesta a la cultivada por el positivismo del siglo anterior. Las teorías de Einstein, primero, y el "principio de incertidumbre" elaborado por Werner Heisenberg en 1927, no dejaron resquicios para las certezas. Por ello, me parece digno de atención que Heisenberg sea justamente citado en una novela que resume toda la época "finisecular" (del siglo XX) de la siguiente manera: "Lo que observamos no es la naturaleza en sí, o la naturaleza de la realidad, sino la naturaleza expuesta a nuestro método de cuestionamiento". (Valenzuela, 2001: 79).

Si la ciencia (y la novela con ella) avanza en esa dirección, también lentes cada vez más complejas enseñaron a nuevas generaciones a desconfiar de la supuesta unicidad de la materia así como, por ejemplo, de la supuesta simplicidad de la naturaleza en la composición de los cristales. La desconfianza hacia cualquier gesto de inocente realismo en la escritura de ficción (y de sus arrabales) llevó, particularmente, a los escritores y a las escritoras del Río de la Plata a avanzar en un campo minado por los sucesos políticos, vividos en décadas anteriores. El debate sobre el realismo literario y sus adyacencias estuvo marcado, según Miriam Chiani, por las discusiones que abrieron las novelas de Aira así como las de Laiseca y de los escritores nucleados alrededor del grupo denominado "Shangai" en la década de los 80 (Chiani, 2001: 30). Las desilusiones del realismo socialista, con sus ecos en el grupo llamado de "Boedo" en los 30, así como el debate en contra del "compromiso sartreano" liderado por la revista Contorno en los 50 (puesto en la picota en os 80) habían sido el preludio de una desconfianza ante cualquier "realismo" que los avances en las

$14 \underline{O f i c i o S}_{\text {Terrestres }}$ 
ciencias no hicieron más que agudizar. La amplia gama de narraciones semi-ficcionales como memorias y testimonios de la época del terrorismo de Es tado puso en cuestión asimismo las fronteras de la misma categoría reverenciada de ficción y "contaminó" las definiciones que todavía sirven, a pesar de todo, para separar en dos mundos dicotómicos la sección de los libros más vendidos en los mensajes habituales de fiction/non-fiction de las publicaciones periódicas. La literatura testimonial en el Río de la Plata fue, por cierto, la expresión de un males tar que creció durante esta última década en la región, pero, a mi modo de ver, ese crecimiento estuvo (in-)directamente conectado con la autopercepción de aquello que hasta mediados del siglo se consideraba a sí misma literatura mimética. En esta ola de barrimientos de certezas, los autores de ambos sexos fueron cómplices en la elección de una variedad de géneros narrativos que abarcó un espectro mayor. Las escritoras fueron, por cierto, igualmente sensibles a los cambios. Sus obras pueden verse, por ello, como una especie de especia sismógrafo de los movimientos de base, en tanto ellas estuvieron desde más antiguo marginadas en ese sentido, fueron y son figuras paradigmáticas de una percepción distinta de los cambios del entorno y de las circunstancias de construcción de un paisaje que se parece mucho a un campo después de la batalla, es decir con perfiles poco nítidos sobre lo que ha sucedido y lo que anuncia el futuro.

Por ello, coincido con José Luis de Diego, cuando este investigador en su contribución a la nueva historia de la literatura dirigida por Noé Jitrik, titulada "Relatos atravesados por los exilios", señala que en el texto autobiográfico de Tununa Mercado de 1990, En estado de memoria: "la intensidad de la experiencia muestra sus efectos sobre el cuerpo, sobre la percepción y sobre los modos de construir el relato y sus figuras" (Jitrik, 2000: 449). La marca del cambio en esta vuelta de página de la mirada masculina sobre lo escrito por mujeres puede documentarse justamente en la definitoria cesura que establece la década de los 60, cuando las mujeres escritoras aparecen ya como un grupo distintivo en el panorama literario rioplatense, que, aunque pequeño empieza a hacerse notar con cualidades propias y que sólo puede ser apreciado, sin embargo, como contraste de la situación sentada por los varones. Como ejemplo de esto puede señalarse una afirmación de Luis Grigorich quien sostenía al respecto:

"Se trata ahora de novelistas y cuentistas seguras de su oficio, en general alejadas de toda propensión "femenina" a la prosa confesional o al des fogue lírico, y preocupadas, como sus compañeros de generación, en estructurar novelísticamente los problemas históricos, psicológicos y sociales de su país". (Prieto, 1968-1976: 1212)

Es, por ello, que los consejos recalcitrantes de Elías Castelnuovo a una escritora en 1949, vedándole la introspección psicológica en tanto mujer aparecen como anécdotas de un pasado falocrático, según nos advierte Elsa Drucaroff en su artículo titulado "Pasos nuevos en espacios diferentes", donde se citan estas palabras paternalistas redescubiertas por Claudia Bernazza en 1995:

"Sabe usted escribir, sabe pensar y también construir. Su fuerte, no obstante, a mi juicio, es su punto vulnerable. Porque su fuerte -el psicoanálisis- es de doble filo. Para frecuentar los así llamados territorios nocturnos del alma y proyectar allí alguna luz se requiere una valentía y una franqueza difícil en el hombre, casi insalvable en una mujer". (Jitrik, 2000: 465, nota 14)

Si el presente artículo se ocupa de dos autoras relativamente fuera del canon, ello ha sido con el fin de corregir la mirada masculina, y llamar a una mayor visibilidad tanto la obra de Tununa Mercado, 
descubierta por la pionera editorial Jorge Álvarez en 1967, como la más reciente de la joven escritora Matilde Sánchez. Ambas autoras, por otra parte, deben seguir padeciendo cierta marginalidad de circulación. Así es significativo que Tununa Mercado en un relato titulado "Asamblea", narre las vicisitudes por las que pasa la conciencia femenina para tomar la palabra en un coro de hombres:

"La palabra dice: Dejen hablar a la compañera, silencio, dejen hablar a la compañera. Pero compañeros... La interrupción atenta contra la democracia y lesiona el sentido de la reunión, en la que queremos que todos expresen su opinión con libertad, dice la compañera, disparando una pequeña carga de culpas. El silencio se hace; ella habla con calma, con la serenidad aprendida. Pero, de pronto, empieza a enredarse, inconteniblemente a desbarrancarse. Une, desanuda, ata, desata, escoge cabos que estaban pendientes en un esfuerzo desesperado por equilibrar. El descontrol es más fuerte. Aparecen superficies sin asidero, no hay de donde agarrarse, todo se desploma en un gigantesco chubasco para luego reincorporarse en un haz de chorros, como de fuente romana. Surgente, insurgente, el discurso trastabilla.

El consenso se impacienta. La ola ha remontado demasiado alto y se rompe sobre paredes compactas. Estólido consenso, no quiere escuchar". (Mercado, 1988: 85).

La tremenda ironía de esta tímida toma de palabra, es que la voz narradora logra expresar y hacerse a oír con un grado perfecto de inteligibilidad (pues detrás de esa voz titubeante se percibe la inquietud minimalista de Tununa Mercado que marca inflexiones del texto mediante el uso sugerente de las cursivas). Así este fragmento sólo se ocupa de algo menor: mostrar las vicisitudes de la lucha de la mujer en un mundo dominado por la estentoriedad de la voz masculina. Ningún escritor varón podría haber representado de esta manera esa condición de minusvalidez.

En cuanto a Matilde Sánchez vale la pena recordar que la misma Historia crítica de la literatura argentina, dirigida por Noé Jitrik, (dedicada en su tomo 11 a la producción literaria más reciente) sólo la menciona fugazmente una vez (Jitrik, 2000: 43). Su segunda novela, El Dock, sin embargo, parece concentrar todos los fantasmas y el completo imaginario de la década de los 90. En ella, la narradora expone no sólo la devastación dejada por el terrorismo de Estado de años antes, sino que, al mismo tiempo, se encarga de mostrarnos la especial aptitud de la mujer para construir puentes donde es el principio de lo relacional lo que importa, mucho más que aquel de la autonomía que preocupa al varón (Kilgour, 1995: 37). Allí encontramos, además de la protagonista narradora, a Leo, el niño muy inteligente $y$, al mismo tiempo, hasta cierto punto encerrado en un mundo autista. A pesar de ese autismo, Leo logra establecer una comunicación con su nueva figura materna (la narradora), gracias a un lento trabajo de aprendizaje de lo que significa la relación madre-hijo desde los dos polos de la relación. Esa creación de puentes humanos, nos dice la novela, trasciende las determinaciones biológicas. El relato se encarga, por ello, de destruir los mitos sobre la maternidad como destino manifiesto y único de la mujer, transformando esa situación en un proceso de adaptación y elección de las respectivas posiciones de "madre" y de "hijo" por cada uno de los actantes. Al instalar ante el lector semejante proceso de amoldamiento a las circunstancias cruentas de la historia social y del entorno, la novela de Sánchez juega a sabiendas con la experimentación, sabiendo de antemano que el texto peligra al borde de un abismo y que no deberá tornarse un melodrama de re-encuentros familiares. $Y$ para salir al encuentro del melodrama y subvertirlo, esta novela combate, por una parte, tanto un realismo posible como un simbolismo que pretendiera 
crear hitos altisonantes de hechos cotidianos. También El dock se cierra con la tímida esperanza de aquello que preocupa a la mujer (y debería preocupar también a los hombres): la comprensión de otro. La narradora nos muestra lo que queda después de la batalla en un adentro y un afuera de la nueva relación "maternal" que aparece como promisoria y constructiva:

"Afuera el viento batía las ramas del pino contra el alero. Oímos desplomarse las reposeras. Eran los perros vagabundos que escaparon del portón y ahora habían encontrado refugio en la galería". (Sánchez, 1993: 301).

Para concluir, se podría decir que, en la pasada década en la Argentina, las narradoras de "lo mínimo" así como aquellas de "lo máximo" han coincidido en mirar de modo descentrado la ubicación de lo femenino en la cultura argentina y, finalmente, aportar, con conocimiento de causa, cómo siente y qué quiere la mujer en este rincón inmenso y pequeñito del mundo que es el Río de la Plata, sintiéndose compañeras y, a la vez, revisoras del discurso instalado por el varón en la maraña de los signos de esa sociedad ya definitivamente embarcada en una modernización, a pesar de los avatares económicos.

\section{Bibliografía}

-CHIANI, MIRIAM. "Represión, exilio, utopía y contrautopía. Sobre Marcelo Cohen". En: Orbis Tertius, revista del Centro de Estudios de Teoría y Crítica Literaria, FAHCE, UNLP, Al Margen, La Plata, 2001 número 8, pp. 21-32

-DE DIEGO, JOSE LUIS. ¿Quién de nosotros escribirá el Facundo? Intelectuales y escritores en Argentina (1970-1986), Al Margen, La Plata, 2001.

-JITRIK, NOÉ. (Director del proyecto). Historia crítica de la literatura argentina, volumen 11 (directora del volumen: Elsa Drucaroff) La narración gana la partida, Emecé Editores, Buenos Aires, 2000.

-KILGOUR, MAGGIE. The Rise of the Gothic Novel, Routledge, Londres/N.York, 1995.

-LORENZANO, SANDRA. Escrituras de sobrevivencia. Narrativa argentina y dictadura, Universidad Autónoma Metropolitana/ Beatriz Viterbo, México/Rosario, 2001

-LUDMER, JOSEFINA. (Compiladora), Las culturas de fin de siglo en América Latina, Beatriz Viterbo, Rosario, 1994.

-MASIELLO, FRANCINE. Entre civilización y barbarie Mujeres, Nación y Cultura literaria en la Argentina moderna, (1992), Beatriz Viterbo, Rosario, 1997.

El arte de la transición, Norma, Buenos Aires, 2001

-PERILLI, CARMEN. Las ratas en la torre de Babel. La novela argentina entre 1982 y 1992, Letra Buena, Buenos Aires, 1994.

-PRIETO, ADOLFO. (Director del proyecto), Historia de la literatura argentina, Centro Editor de América Latina, Buenos Aires, 1968-1976 (3 tomos). 